e-ISNN: 2359-5078

\title{
Déficit de armazenagem da produção agrícola do Tocantins
}

Storage shortfall of agricultural production in Tocantins

\author{
Rafael Alves da Silva ${ }^{1}$; Flávio Carlos Dalchiavon ${ }^{2 *}$
}

${ }^{1}$ Companhia Nacional de Abastecimento - Analista/Engenheiro Agrícola - Superintendência Regional do Tocantins - Quadra 601 Sul - Avenida Joaquim Teotônio Segurado Conjunto 01 - Lote 02 - 77016-330 - Palmas, TO - Brasil

$2^{2 *}$ Instituto Federal de Educação, Ciência e Tecnologia de Mato Grosso - Engenheiro Agrônomo - Doutor em Agronomia - Campus Campo Novo do Parecis - Rodovia MT 235 - km 12, s/n - Caixa Postal n 100 - Zona Rural - 78360-000 - Campo Novo do Parecis, MT - Brasil <flavio.dalchiavon@cnp.ifmt.edu.br>

\section{Resumo}

O Tocantins é um grande produtor de grãos da região Norte do Brasil, porém, como outras importantes regiões do país em produção de grãos, não conta com infraestrutura adequada para armazenagem. Objetivou-se comparar o histórico da produção de grãos do Tocantins com a capacidade estática dos seus armazéns entre o período de 1990 a 2017, definindo os municípios e/ou regiões com maior potencial para instalação de novos empreendimentos de armazenagem. Utilizou-se como referência os dados de produção de grãos e dos armazéns cadastrados, ambos disponíveis na Companhia Nacional de Abastecimento, para avaliar a evolução e elaborar mapas da distribuição geográfica da capacidade estática e do déficit de armazenagem. O Tocantins se tornou, nos últimos anos, um dos principais produtores de grãos na região Norte do Brasil e ainda apresenta grande potencial de crescimento. Mesmo havendo crescimento na capacidade estática de armazenagem, este não tem acompanhado o crescimento da produção de grãos, o que justifica atualmente o déficit de armazenagem da produção em aproximadamente 2.512 .305 de toneladas, representando 57,97\% da produção total de grãos do estado. As regiões ou municípios que apresentam maiores déficits em capacidade estática e, consequentemente, melhores oportunidades para novas instalações na área de armazenagem são: Porto Nacional, Campos Lindos, Dianópolis, Lagoa da Confusão, Peixe, Caseara, Gurupi, Goiatins, Pium e Miracema do Tocantins.

Palavras-chave: agronegócio, capacidade estática, estocagem de grãos, milho, soja

\begin{abstract}
Tocantins is a major grain producer in the northern region of Brazil. However, as well as other regions that are relevant in grain production, it does not have an adequate storage infrastructure. This study aims to compare the history of grain production in Tocantins with the static capacity of its warehouses between 1990 and 2017 and define the municipalities and/or regions with the greatest potential for the installation of new storage enterprises. The grain production and registered warehouses data (available at the Companhia Nacional de Abastecimento) were used as reference to assess the progress and draw up maps of the geographical distribution of static capacity and storage shortfall. Tocantins has become, in recent years, one of the main grain producers in the northern region of Brazil and it still presents great growth potential. Despite the growth in the static storage capacity, it has not followed the growth of grain production and this justifies the production shortfall of approximately 2,512,305 tons, which represents $57.97 \%$ of the state's total grain production. The regions or municipalities that have the greatest deficits in static capacity and, consequently, better opportunities for new storage facilities are: Porto Nacional, Campos Lindos, Dianópolis, Lagoa da Confusão, Peixe, Caseara, Gurupi, Goiatins, Pium and Miracema do Tocantins.
\end{abstract}

Keywords: agribusiness, static capacity, grain storage, corn, soybean

\section{Introdução}

Com área territorial de $277.720,57 \mathrm{~km}^{2}$ e composto por 139 municípios, o estado do Tocantins ocupa a $10^{\mathrm{a}}$ posição dentre os estados brasileiros de maior extensão territorial (IBGE, 2016). O estado desponta como o "novo polo agrícola do Brasil" e com grande potencial de expansão da área de cultivo, sendo que aproximadamente metade do seu território (13.825.070 ha) possui potencial agrícola (SEAGRO, 2016). Conforme dados da Companhia Nacional de Abastecimento [CONAB] (2017a), para a safra 2016/2017, estima-se que o Tocantins deverá ter uma produção de 4.325.500 toneladas de grãos (milho, soja, sorgo, arroz, feijão, amendoim e algodão) cultivados em cerca de 1.290.400 ha (se somado todas as áreas de cultivo do ano safra), 9,33\% do potencial agricultável do estado.

Como grande parte da produção de grãos é armazenada durante determinado período, várias regiões produtoras de grãos do Brasil, assim como o Tocantins, têm 
enfrentado grandes problemas neste segmento agrícola em decorrência da capacidade estática limitada dos armazéns (Lima Júnior et al., 2012; Maia et al., 2013). De acordo com Elias (2003), a armazenagem é o processo de guardar o produto, associada a uma sequência de operações, tais como limpeza, secagem, tratamento fitossanitário, transporte, classificação, dentre outros, com $\mathrm{o}$ intuito de preservar as qualidades físicas, químicas e biológicas da colheita, até o abastecimento.

O Ministério da Agricultura, Pecuária e Abastecimento [MAPA] (2011) define Unidade Armazenadora [UA] como edificações, instalações e equipamentos organizados funcionalmente para a guarda e conservação dos produtos agropecuários, seus derivados, subprodutos e resíduos de valor econômico. O órgão separa as unidades armazenadoras em quatro tipos: 1) em nível de fazenda - localizada em propriedade rural, com capacidade estática e estrutura dimensionada para atender ao próprio produtor; 2) coletora - localizada na zona rural (inclusive nas propriedades rurais) ou urbana, com características operacionais próprias, dotada de equipamentos para processamento de limpeza, secagem e armazenagem com capacidade operacional compatível com a demanda local; 3) intermediária - localizada em ponto estratégico de modo a facilitar a recepção e o escoamento dos produtos provenientes das unidades armazenadoras coletoras, e; 4) terminal - localizada junto aos grandes centros consumidores ou nos portos, dotada de condições para a rápida recepção e escoamento do produto, caracterizada como unidade armazenadora de alta rotatividade.

A pessoa jurídica que executa a armazenagem dos produtos agropecuários tem o dever de solicitar sua inclusão no Sistema de Cadastro de Armazém de Produtos Agrícolas [SICARM], administrado e controlado pela CONAB (Brasil, 2001). Apesar da obrigação do cadastramento no SICARM, pode acontecer de a UA estar operando sem realizar o seu cadastramento e ficar de fora da avaliação, uma vez que não há fiscalização e/ou multa pelo não cumprimento da obrigação.

De acordo com o MAPA (2011), a certificação da UA é obrigatória para as pessoas jurídicas que prestam serviços remunerados de armazenagem, a terceiros, de produtos agropecuários, seus derivados, subprodutos e resíduos de valores econômicos, inclusive de estoques públicos. Trata-se do reconhecimento formal, concedido por um organismo autorizado, de que uma entidade tem competência técnica para realizar serviços específicos e tem como objetivo de ser um indicador para os consumidores de que as atividades desenvolvidas pelo prestador de serviços atendem ao padrão de qualidade.

A implementação de armazenagem nas fazendas de regiões produtoras de grãos, onde a demanda de armazenagem seja elevada poderá elevar o nível de renda do produtor, que terá redução nas perdas e riscos decor- rentes das flutuações dos preços, contribuindo para o desenvolvimento da comercialização. A implementação também favorecerá os consumidores, com o abastecimento contínuo e benefícios com preços mais estáveis (Silva et al., 2008).

A UA, técnica e convenientemente localizada, constitui uma das soluções para tornar o sistema produtivo mais econômico, propiciando a comercialização da produção em melhores períodos, evitando as pressões naturais do mercado na época da colheita (D’Arce, 2009). A guarda de produto na propriedade apresenta inúmeras vantagens: a minimização das perdas quantitativas e qualitativas no campo; economia do transporte; maior rendimento na colheita por evitar a espera dos caminhões nas filas nas unidades coletoras ou intermediárias; a obtenção de financiamento por meio das linhas de crédito específicas para a pré-comercialização; redução dos custos de transação; disponibilidade do produto para utilização oportuna, além de implicar na redução das filas nos terminais de exportação, constituindo-se em alternativa para fugir dos gargalos logísticos (Nogueira Junior e Nogueira, 2007; Giovine e Christ, 2010).

Nesse contexto, objetivou-se comparar o histórico da produção de grãos do Tocantins com a capacidade estática dos seus armazéns entre o período de 1990 a 2017, definindo os municípios e/ou regiões com maior potencial para instalação de novos empreendimentos de armazenagem.

\section{Material e Métodos}

Avaliou-se a evolução da produção de grãos do Tocantins no período de 1990 a 2017, com base nas séries históricas obtidas na CONAB (2017b). Os dados dos armazéns tocantinenses (capacidade estática, localização geográfica, tipo, nível do armazém e número do registro cadastral [CDA] foram obtidos do SICARM (CONAB, 2017c) assim como, os de produção dos municípios/região, contidos no $4^{\circ}$ levantamento da Safra 2016/2017 (CONAB, 2017a).

Como a produção de grãos foi estimada para o ano safra " $\mathrm{x} / \mathrm{x}+1$ " (período de setembro do ano " $\mathrm{x}$ " a agosto do ano " $\mathrm{x}+1$ ") e os dados de capacidade estática dos armazéns foram avaliados em outra escala de tempo, o ano civil (período de janeiro a dezembro), adotou-se ajustes para realizar uma comparação dessas variáveis. Para a produção de grãos, a quantidade foi realocada para o ano do encerramento do período safra, ou seja, para $\mathrm{o}$ ano " $\mathrm{x}+1$ " do ano safra. Como exemplo, no caso da produção de grãos do ano safra 2014/2015, correspondente a $4.217,7$ mil toneladas, esta foi considerada toda no ano 2015.

Para a análise da falta de armazenagem (déficit de armazenagem), adotou-se a diferença entre a capacidade estática e a produção total de grãos (incluso a safra e 
safrinha) por município e, em alguns casos, por regiões em razão da metodologia do Levantamento de Safras realizado pela CONAB. Espera-se que as regiões ou municípios com maior déficit de armazenagem correspondam às regiões com maiores demandas pelos serviços de armazenagem e, consequentemente, maior a oportunidade para instalação de novos armazéns.

As estimativas de crescimento médio anual da produção de grãos e da capacidade estática de armazenagem foram realizadas pelo método geométrico eq. (1):

$$
T x=\left[\left(\frac{V f}{V i}\right)^{\frac{1}{n}}-1\right] \times 100
$$

onde, Tx: é a taxa média de crescimento anual, Vf: é o valor no período final, Vi: é valor no início do período avaliado e n: é igual ao número de anos no período.

No georreferenciamento das UAs, utilizou-se o software "Google Earth Pro" e suas imagens de satélite para conferir as coordenadas obtidas no SICARM (CONAB, 2017c). Em alguns casos foi necessário a conversão das coordenadas no sistema sexagesimal (graus, minutos e segundos) para graus decimais, além de outros ajustes manuais para obter a localização correta. Em um segundo momento, utilizou-se arquivos vetoriais correspondentes à base digital do Brasil que dispõem dos polígonos delimitadores de cada município do país e à BR-153 no formato "shapefile", disponibilizados no portal eletrônico do Instituto Brasileiro de Geografia e Estatística [IBGE] (2015), e do Departamento Nacional de Infraestrutura de Transportes [DNIT] (2015), respectivamente, para a elaboração dos mapas da distribuição da capacidade estática e déficit de armazenagem no "software" ArcGIS, ambos os mapas estão no "Datum- World Geodetic System" [WGS] do ano de 1984.

\section{Resultados e Discussão}

Entre o ano safra 2004/2005 e 2016/2017, a produção de grãos no Tocantins cresceu a uma taxa média anual de 7,34\% (Figura 1). O milho em grãos ( $2^{\mathrm{a}}$ safra), geralmente cultivado após a colheita da soja ( $1^{\mathrm{a}}$ safra), foi a cultura que apresentou a maior taxa média de crescimento anual $(54,41 \%)$, seguida da soja ( $1^{\mathrm{a}}$ safra), com $9,25 \%$, porém, para a safra $2016 / 2017$, a estimativa é que a soja ( $1^{\mathrm{a}}$ safra) chegue ao valor de 2.637.690 toneladas, representando $60,86 \%$ do total de grãos a ser produzido.

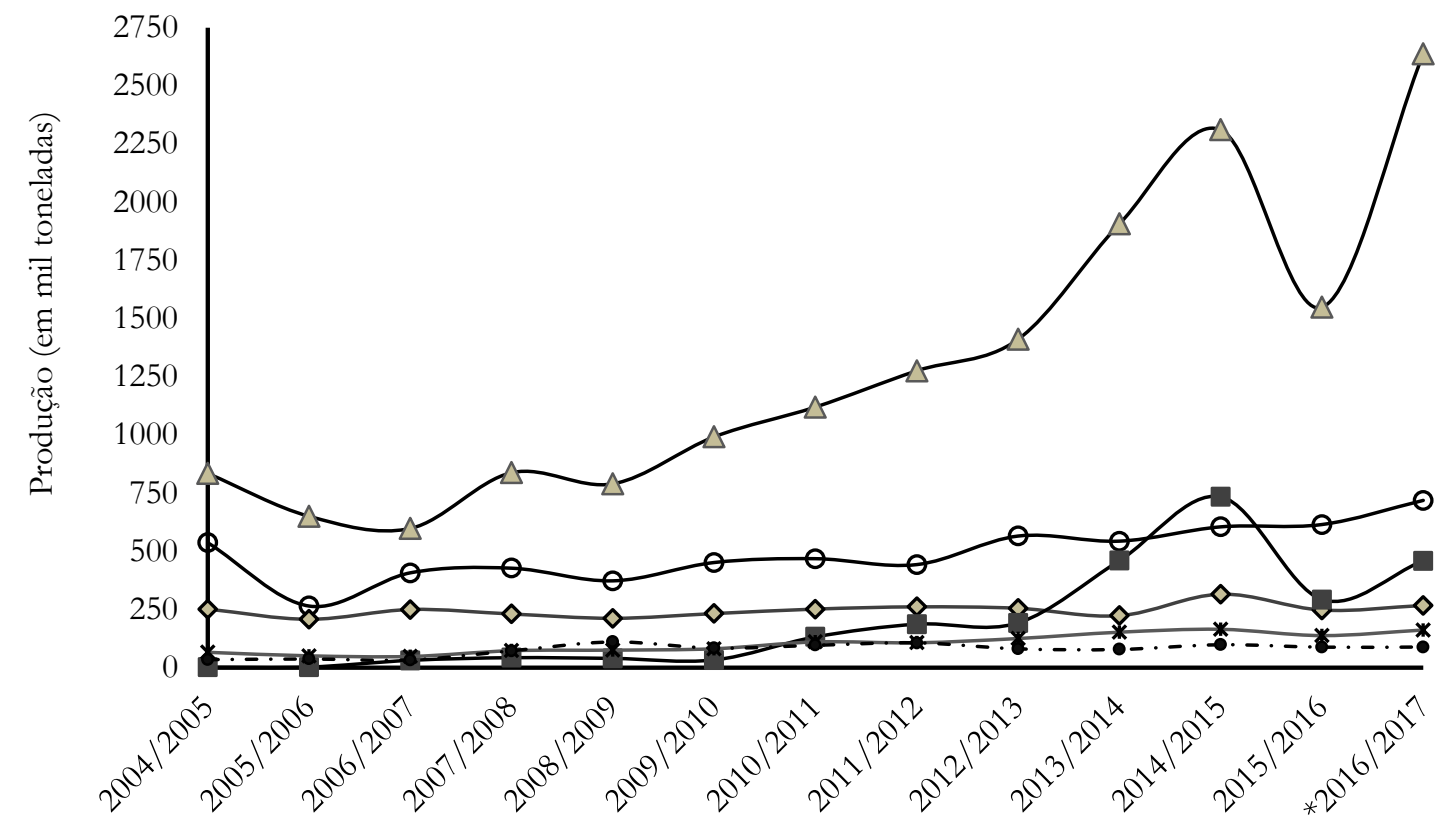

Ano Safra
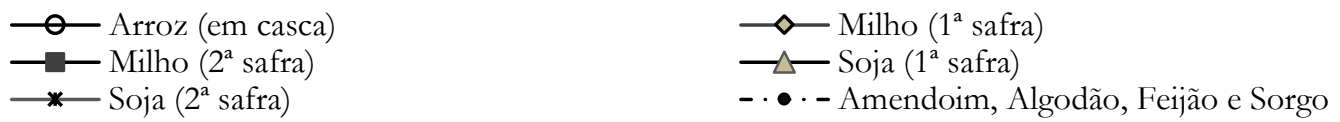

Figura 1. Evolução da produção de grãos no Tocantins entre a safra 2004/2005 e 2016/2017

Nota: * A produção de grãos do ano safra 2016/2017 é referente ao $4^{\circ}$ Levantamento de Safra de Grãos do Tocantins, divulgado em janeiro de 2017 Fonte: CONAB (2016, 2017a) 
Entre o período de 2003 a 2013, enquanto o Brasil obteve crescimento médio anual na produção de grãos de $8,48 \%$, o Tocantins obteve $16,47 \%$, sendo o efeito do aumento da área responsável por $8,57 \%$ do crescimento da produção do estado, seguido do efeito da produtividade $(3,21 \%)$ e da mudança na produção relativa à proporção da área total cultivada com diversas culturas (4,69\%), conforme relataram Perobelli et al. (2016). Relataram ainda que o efeito área foi um importante componente no Centro-Oeste do Brasil, o que permitiu afirmar que, para o período analisado, houve uma continuidade de expansão de fronteira de produção por meio da expansão de terras aproveitadas para a produção agrícola.

De acordo com o SICARM (CONAB, 2017c), o estado do Tocantins têm 150 UAs cadastradas com capacidade estática total de 1.821 .698 toneladas, sendo 53 UAs convencionais, com capacidade estática de 314.469 toneladas, e 97 granelizadas, capacidade 1.507.229 tonelada). Apenas 4 UAs, com capacidade estática total de 93.740 toneladas, estão certificadas, correspondendo a $5,15 \%$ do total da capacidade estática e a $2,7 \%$ da quantidade de armazéns do Tocantins, valores bem inferiores ao estabelecido pelo MAPA.

Conforme o MAPA (2013), até o prazo de $31 / 12 / 2016$, empresas prestadoras de serviço de armazenagem deveriam ter no mínimo $60 \%$ da capacidade estática, ou da quantidade de Cadastros Nacionais da Pessoa Jurídica [CNPJ] certificadas. No caso de empresas com até três CNPJs ou até três CDAs, com capacidade estática máxima total de 20.000 toneladas, deveriam ser escalonadas da seguinte forma: um CNPJ ou CDA, deveria ser certificado até 31/12/2014; dois CNPJs ou CDAs até 31/12/2014 para primeira unidade e 31/12/2015 para a segunda unidade e três CNPJs ou três CDAs, até $31 / 12 / 2014$ para primeira unidade, $31 / 12 / 2015$ para a segunda unidade e 31/12/2017 para terceira unidade.

Portanto, de acordo com o SICARM (CONAB, 2017c) e o MAPA (2013), exceto os quatro armazéns certificados de CDA n ${ }^{\circ}$ 80.B257.0004-0, 80.D376.00015, 80.B257.0003-2 e 80.B257.0005-9, todos os demais armazéns tocantinenses não estão habilitados pelo escalonamento de certificação ou não estão certificados e, consequentemente, encontram-se irregulares para prestar serviços a terceiros, inclusive ao governo federal. No caso das UAs da CONAB, de iniciativa pública e vinculadas ao MAPA, também encontram-se inabilitadas por não cumprirem o escalonamento estabelecido pelo MAPA e, consequentemente, deveriam estar impedidas de prestar serviços de armazenagem.

Conforme dados do SICARM (CONAB, 2017c), existe uma concentração da capacidade de armazenagem nos municípios de Lagoa da Confusão e Formoso do Araguaia, correspondendo juntos a cerca de 34,17\% da capacidade estática do estado. Como característica, conforme dados do levantamento de safras da CONAB, tradicionalmente os dois municípios apresentam grandes áreas de cultivo de arroz irrigado, com produção de 437.070 toneladas na safra 2015/2016, correspondendo a $77,86 \%$ do total de arroz irrigado e $14,92 \%$ da safra total de grãos do Tocantins (CONAB, 2016).

Apenas 40 dos 139 municípios do estado têm UAs cadastradas (Figura 2), 10 deles (Lagoa da Confusão, Formoso do Araguaia, Campos Lindos, Cariri do Tocantins, Porto Nacional, Santa Rosa do Tocantins, Pedro Afonso, Silvanópolis, Gurupi e Paraíso) concentram cerca de $74,23 \%$ da capacidade estática tocantinense.

Muitas UAs estão situadas próximas à sede municipal, tais como as do município de Lagoa da Confusão. Caso estejam dentro do perímetro urbano, a médio e longo prazo, estes empreendimentos poderão ter dificuldades com o fluxo intenso de caminhões pela cidade, podendo até serem prejudicados por uma possível proibição no trânsito destes veículos em algumas vias urbanas. Conforme dados do SICARM, 15,21\% da capacidade de armazenagem do Tocantins encontram-se localizada na zona urbana.

Enquanto em países desenvolvidos o sistema de armazenagem principal está concentrado ao nível de fazenda e secundariamente a participação em capacidade estática evolui para as unidades ao nível de coletoras, intermediárias e terminais, o Brasil ainda apresenta este cenário oposto. Na Argentina, Austrália, Canadá, Estados Unidos da América e na Europa, a participação dessas unidades é de $40 \%, 35 \%, 85 \%$, 65\% e 50\%, respectivamente. No Brasil apenas $24 \%$ da capacidade estática está localizada nas fazendas, o que totaliza 20,10 milhões de toneladas (Fernandes e Rosalem, 2014). Estes números revelam o quanto a capacidade de armazenagem ao nível de fazenda no Brasil é pequena. A realidade do Tocantins não é diferente, apenas $17 \%$ da capacidade estática está localizada na fazenda (CONAB, 2017c).

As UAs localizadas em áreas rurais, mas fora das fazendas produtoras, próximas das rodovias e ferrovias, que são importantes para o escoamento da produção agrícola, correspondem a $67,75 \%$ da capacidade estática de armazenagem do estado (CONAB, 2005, 2017c). Em suma, conforme dados do SICARM, 83\% da capacidade estática do Tocantins estão além da porteira, o que fornece suporte à argumentação de que parcela significativa da perda da rentabilidade do produtor tem origem nesse fato. As perdas quantitativas e qualitativas que ocorrem no campo pelo atraso da colheita, por falta de secagem ou armazenamento em locais inadequados, depreciam o valor da produção (CONAB, 2005). 


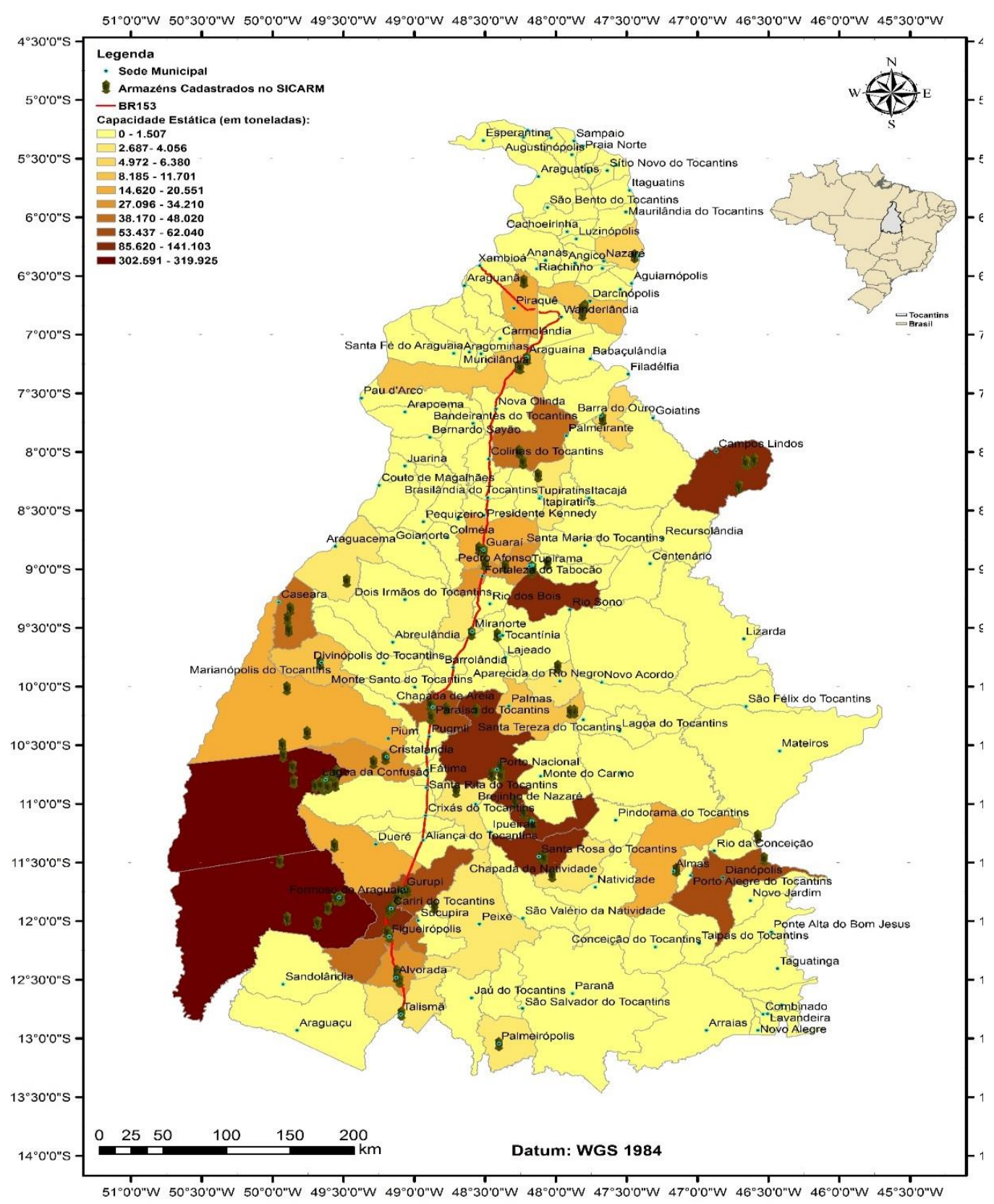

Figura 2. Capacidade éstática das Unidades Armazenadoras do Tocantins cadastradas no Sistema $\overline{\text { de }}$ Cadastro Nacional de Unidades Armazenadoras

Fonte: CONAB (2017a, c)

Ao longo da rodovia BR-153, rota de escoamento da produção agrícola do Tocantins, existem várias sedes municipais e UAs instaladas de forma estratégica para facilitar o escoamento da produção. Segundo Tavares (2017), grande parte da produção de soja e milho tocantinense é escoada pelo Corredor Tocantins. Primeiramente, via rodoviária até os terminais ferroviário de Palmeirante TO e, em seguida, via ferroviária (ferrovia Norte-Sul) até o porto de São Luís - MA. Mesmo existindo, há mais de dois anos, vias férreas instaladas de Anápolis - GO à São Luís - MA, a produção de grãos do nordeste do
Mato Grosso, região do MATOPIBA e norte de Goiás é transportada via ferroviária somente a partir do Norte do Tocantins.

A partir de 2008, a quantidade de grãos produzidos no Tocantins foi superior a sua capacidade estática de armazenagem (Figura 3). Enquanto a produção de grãos teve uma taxa de crescimento média anual de $9,29 \%$, no período de 1990 a 2017, a capacidade de armazenagem cresceu a uma taxa média anual de $3,60 \%$, o que justifica a situação atual da armazenagem no estado. 


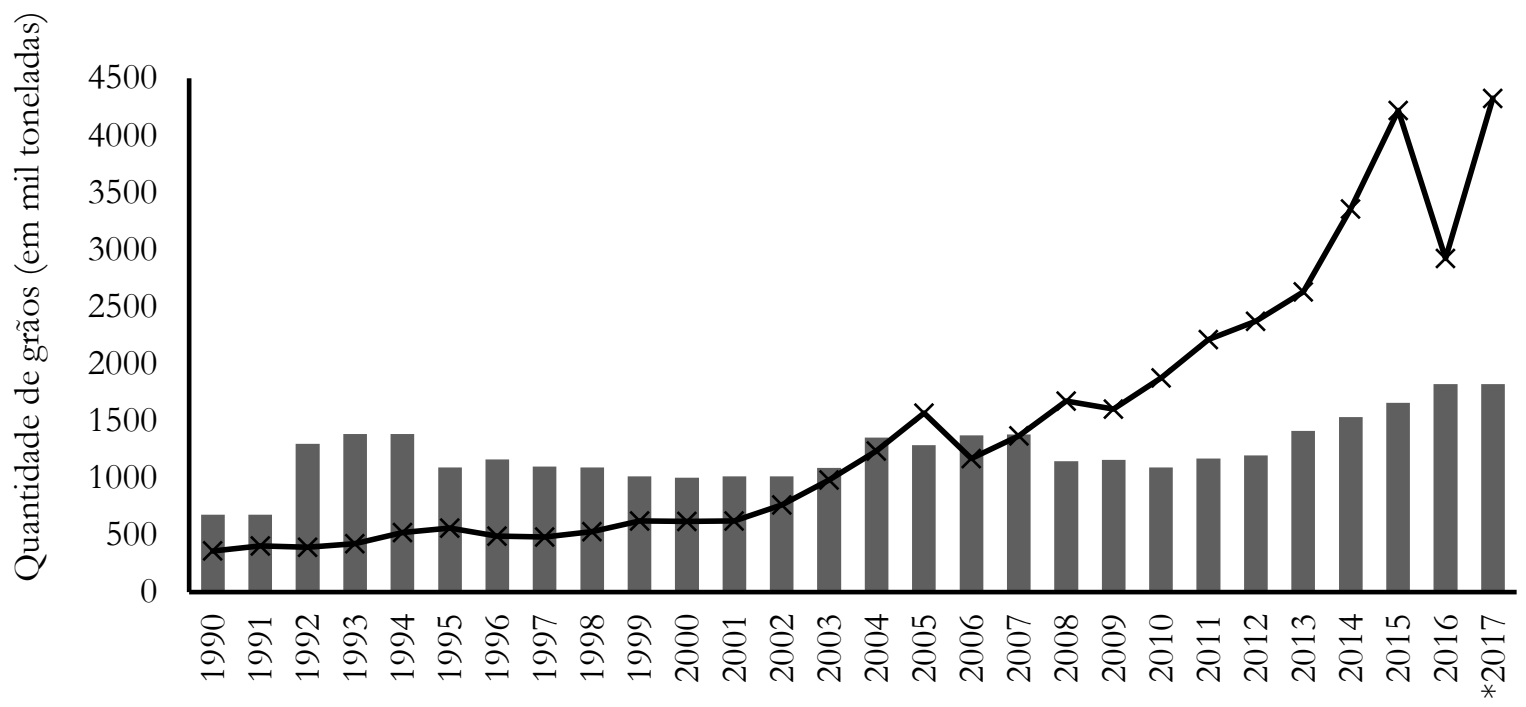

Ano

\section{Capacidade Estática $\quad$ * Produção de Grãos}

Figura 3. Evolução da produção de grãos e da capacidade estática dos armazéns do Tocantins, de 1990 a $2017^{*}$

Nota. * A produção de grãos do ano 2017 é referente ao $4^{\circ}$ Levantamento de Safra de Grãos do Tocantins do ano safra 2016/2017, divulgado em janeiro de 2017

Fonte: CONAB (2017a, b, c, d)

O déficit de armazenagem do Tocantins, calculado pela diferença do total de capacidade estática dos armazéns pela estimativa da produção de grãos na safra 2016/2017, foi cerca de 2.512.305 toneladas (CONAB, 2017a, c). O município de Formoso do Araguaia e a região de Tocantinópolis apresentaram uma capacidade estática superior à quantidade de grãos produzida, cujo saldo de armazenagem corresponde à quantidade de 65.867 e 1.223 toneladas, respectivamente (Figura 4). No entanto, para as demais áreas do mapa houve déficit de armazenagem. A região de Porto Nacional foi a que apresentou o maior déficit, com cerca de 367.071 toneladas (14,61\% do total), seguidos por Campos Lindos, com 239.030 toneladas $(9,51 \%)$, região de Dianópolis, com 176.872 toneladas (7,04\%), Lagoa da Confusão, com 161.937 toneladas $(6,45 \%)$, Peixe, com 148.686 toneladas $(5,92 \%)$, Caseara, com 141.983 toneladas $(5,65 \%)$, região de Gurupi, com 131.537 toneladas (5,24\%), região de Goiatins, com 131.204 toneladas (5,22\%), Pium, com 105.071 toneladas $(4,18 \%)$ e região de Miracema do Tocantins, com 100.409 toneladas $(4,00 \%)$.

Os demais municípios ou regiões apresentaram déficit inferior a 100.000 toneladas, quando somados, o déficit chegou a 808.505 toneladas, o que corresponde a cerca de $32,18 \%$ do déficit de armazenagem do estado (Figura 4). Pode acontecer de áreas de produção se concentrarem em limítrofes municipais ou regionais e, quando somadas às áreas de outro munícipio/região vizinha e na mesma condição, serem as melhores oportunidades para armazenagem. Este trabalho não levou em consideração o local exato das áreas de produção.

Como trabalho complementar à definição das melhores oportunidades para construção de novas UAs, sugere-se o mapeamento das áreas de produção dentro de cada município/região e das principais redes de escoamento dos produtos agrícolas no estado, visando obter um empreendimento de uma UA técnica e convenientemente localizada.

O ideal seria que a capacidade estática de armazenagem no país fosse $20 \%$ superior à estimativa de produção de grãos, servindo como margem de segurança, nos casos de safras recordes e possíveis importações de produtos (Mendes e Padilha Junior, 2007). Seguindo este raciocínio, para o estado de Tocantins, como sua produção de grãos foi de 4.334 .003 toneladas, a capacidade estática ideal deveria ser de 5.200.080 toneladas, o que daria atualmente um déficit de armazenagem de 3.378 .382 toneladas.

Entretanto, ao se usar o padrão universal de rotação de estoques (giro de 1,5 vez) adotado por Nogueira Junior e Tsunechiro (2005), como indicador de viabilidade técnica e econômica para a implantação de uma unidade armazenadora, a capacidade estática de armazenagem do Tocantins (1.821.698 toneladas) seria de 2.732.547 toneladas (capacidade dinâmica), evidenciando, portanto, um déficit menor em torno de 1.601.456 toneladas para o total de grãos estimado para a safra 2016/2017 no Tocantins. 


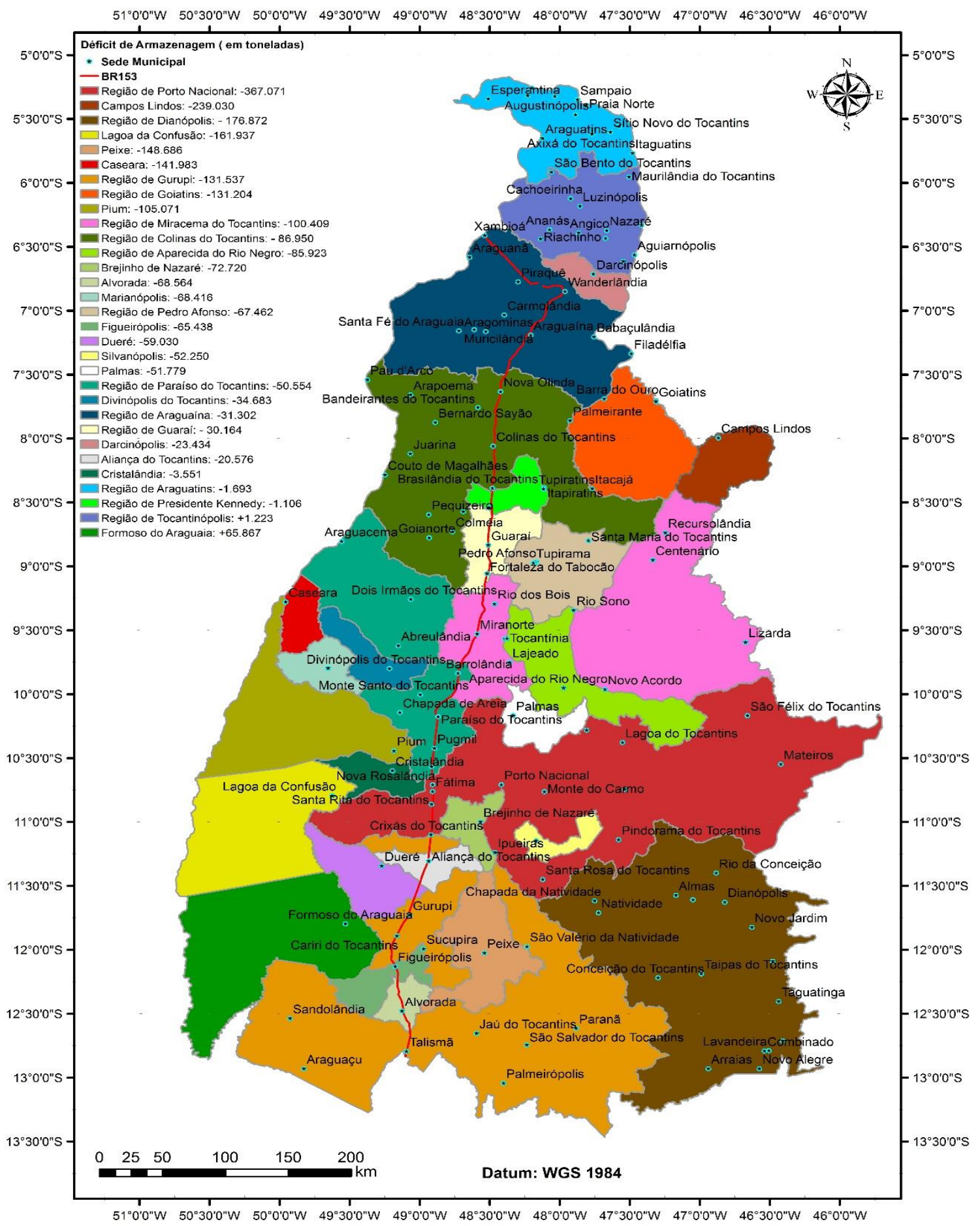

Figura 4. Déficit/saldo de armazenagem de grãos no estado de Tocantins Fonte: CONAB (2017a, c)

Essa rotação de estoque, ou "turnover", pode ser justificada pelas variações estacionais entre as diversas culturas agrícolas, não ocorrendo plena coincidência no calendário de colheita (Nogueira Junior et al., 1989). Além do mais, existe um período limite economicamente viável para a guarda dos produtos, conforme o padrão sazonal de cada um.

Portanto, em função do método de cálculo do déficit de armazenagem, tem-se observado que a falta de armazenagem total do Tocantins variou de $1.601 .456 \mathrm{a}$ 
3.378.382 toneladas, porém, quando calculado pela diferença entre a capacidade estática e a produção de grãos, o déficit foi de cerca de 2.512.305 toneladas, valor considerado na análise das áreas do estado com melhores oportunidades para instalação de UAs. Esse déficit encontra-se dentro do intervalo determinado por outros métodos e próximo do valor médio que foi de aproximadamente 2.489.919 toneladas.

Da mesma forma com que a capacidade estática foi insuficiente no estado, a deficiência de fluxo na capacidade de processamento (pré-limpeza, secagem e limpeza) e movimentação interna de produtos nas unidades armazenadoras, principalmente, naquelas mais antigas, foram fatores que também prejudicaram o rápido escoamento da safra. Isso deve ser levado em consideração na análise mais detalhada das regiões com melhores oportunidades de armazenagem, tendo em vista que as UAs, além de prestarem serviço de armazenagem, podem prestar serviços de processamento (pré-limpeza, secagem e limpeza).

Assim, os investimentos em mais estruturas de armazenagem, nas regiões com elevado déficit de armazenagem, seja a melhor estratégia para o estado do Tocantins e/ou para o país melhorar a distribuição da produção agrícola e a rentabilidade dos produtores agrícolas. A oferta de uma linha de crédito especial para a armazenagem ao nível de fazenda, com juros mais baixos e um período de carência maior, foi uma das formas para o aumento da capacidade estática de armazenagem e, consequentemente, reduzir o déficit de armazéns.

\section{Conclusões}

O Tocantins se tornou nos últimos anos, um dos principais produtores de grãos na região Norte do Brasil apresentando grande potencial de crescimento. No entanto, os investimentos em armazenagem não acompanharam o crescimento da produção. Para se chegar ao ideal no que se refere à capacidade estática de grãos, o estado precisa aumentar em quase 2.512.305 de toneladas de capacidade estática de armazenagem. Isso significa que atualmente o déficit de armazenagem é de aproximadamente $57,97 \%$ da produção total de grãos do estado.

As regiões ou municípios que apresentam maiores déficits de armazenagem e, consequentemente melhores oportunidades para instalação de novas Unidades de Armazenam no Tocantins são: a região de Porto Nacional, Campos Lindos, região de Dianópolis, Lagoa da Confusão, Peixe, Caseara, região de Gurupi, região de Goiatins, Pium e região de Miracema do Tocantins.

\section{Referências}

Brasil. 2001. Decreto n. 3.855, de 13 de julho de 2001. Regulamenta a Lei n 9.973, de maio de 2000, que dispõe sobre o sistema de armazenagem dos produtos agropecuários, e dá outras providências. Disponível em: <https://www.planalto. gov.br/ccivil_03/decreto/2001/d3855.htm>. Acesso em: 02 dez. 2016.

Companhia Nacional de Abastecimento [CONAB]. 2005. Armazenagem Agrícola no Brasil. Disponível em: <http:// www.conab.gov.br/OlalaCMS/uploads/arquivos/7420aabad201bf8d9838f446e17c1ed5..pdf>. Acesso em: 19 fev. 2017.

Companhia Nacional de Abastecimento [CONAB]. 2016. Acompanhamento da Safra Brasileira. Safra 2015/2016. Décimo Segundo levantamento. Disponível em: < http://www.conab.gov.br/OlalaCMS/uploads/arquivos/16_09_21_09_59_00_boletim_12o_levantamento_da_ safra_2015-2016_-_tocantins_-agosto_2016.pdf>. Acesso em: 20 dez. 2016.

Companhia Nacional de Abastecimento [CONAB]. 2017a. Acompanhamento da Safra Brasileira. Safra 2016/2017. Quarto levantamento. Disponível em: < http://www.conab. gov.br/OlalaCMS/uploads/arquivos/17_01_11_11_30_39_ boletim_graos_janeiro_2017.pdf>. Acesso em: 22 jan. 2017.

Companhia Nacional de Abastecimento [CONAB]. 2017b. Série Histórica: Produção de Grãos por Unidade da Federação. Disponível em: <http://www.conab.gov.br/conteudos. php?a $=1252 \& \mathrm{t}=>$. Acesso em: 18 jan. 2017.

Companhia Nacional de Abastecimento [CONAB]. 2017c. Consulta de Capacidade Estática. Disponível em: <http:// sisdep.conab.gov.br/capacidadeestatica/>. Acesso em: 18 jan. 2017.

Companhia Nacional de Abastecimento [CONAB]. 2017d. Evolução da Capacidade Estática dos Armazéns. Disponível em: <http://www.conab.gov.br/OlalaCMS/uploads/arquivos/16_06_16_15_36_52_serie_historica_cadastro_por_ uf.pdf>. Acesso em: 18 jan. 2017.

D’Arce, M.A.B. 2009. Pós colheita e armazenamento de grãos. Departamento de Agroindústria, Alimentos e Nutrição ESALQ/USP. Disponível em: <http://www.esalq.usp.br/ departamentos/lan/pdf/Armazenamentodegraos.pdf $>$. Acesso em: 02 dez. 2016.

Departamento Nacional de Infraestrutura de Transportes [DNIT]. 2015. Modais. Arquivo shapefile. Disponível em: <http://www.dnit.gov.br/mapas-multimodais/shapefiles $>$. Acesso em: 20 jan. 2017.

Elias, M.C. 2003. Armazenamento e Conservação dos Grãos. Pólo de Inovação Tecnológica em Alimentos da Região Sul, Conselho Regional de Desenvolvimento da Região Sul. Pelotas, RS, Brasil. Disponível em: < http://www.ebah.com.br/ content/ABAAAA2bQAG/armazenamento-conservacao-graos>. Acesso em: 02 dez. 2016.

Fernandes, Q.S.; Rosalem, V. 2014. O cenário da Armazenagem no Brasil. Enciclopédia Biosfera, Centro Científico Conhecer 19: 352-360.

Giovine, H.; Christ, D. 2010. Estudo sobre processos de armazenagem de grãos - um estudo de caso - região de Francisco Beltrão - PR. Ciências Sociais Aplicadas em Revistas 10: 139-152.

Instituto Brasileiro de Geografia e Estatística [IBGE]. 2015. Malha Municipal do Tocantins. Disponível em: <ftp://geoftp.ibge.gov.br/organizacao_do_territorio/malhas_territoriais/malhas_municipais/municipio_2015/>. Acesso em: 10 
jan. 2017.

Instituto Brasileiro de Geografia e Estatística [IBGE]. 2016. Área Territorial Oficial. Disponível em: <http://ibge.gov. $\mathrm{br} /$ home/geociencias/areaterritorial/principal.shtm $>$. Acesso em: 10 set. 2016.

Lima Júnior, A.F.; Oliveira, I.P.; Rosa, S.R.A.; Silva, A.J.S.; Morais, M.M. 2012. Controle de Pragas de Grãos Armazenados: Uso e Aplicação de Fosfetos. Faculdade Montes Belos 5: 180-184.

Maia, G.B.S.; Pinto, A.R.; Marques, C.Y.T.; Lyra, D.D.; Roitman, F.B. 2013. Panorama da Armazenagem de Produtos Agrícolas no Brasil. BNDES 40: 161-194.

Mendes, J.T.G.; Padilha Junior, J.B. 2007. Agronegócio: Uma Abordagem Econômica.1ed. Pearson Prentice Hall, São Paulo, SP, Brasil.

Ministério da Agricultura, Pecuária e Abastecimento [MAPA]. 2011. Instrução normativa n. 29, de 08 de junho de 2011. Dispõe sobre os requisitos técnicos obrigatórios ou recomendados para certificação de unidades armazenadoras em ambiente natural. Diário Oficial da União, Brasília, 09 jun. 2011. Seção 1, p.9-15.

Ministério da Agricultura, Pecuária e Abastecimento [MAPA]. 2013. Instrução Normativa $n^{\circ} 24$, de 9 de julho de 2013, do Ministério da Agricultura e Abastecimento. Altera o escalonamento de implantação do Sistema Nacional de Certificação de Unidades Armazenadoras estabelecido na Instrução Normativa $\mathrm{n}^{\circ}$ 41, de 14 de dezembro de 2010. Disponível em: <http://www.conab.gov.br/OlalaCMS/uploads/arquivos/14_08_21_10_55_49_in_mapa_2013_24.pdf>. Acesso em: 23 jan. 2016.

Nogueira Junior, S.; Nogueira, E.A. 2007. Centrais Regionais de Armazenagem como apoio à Comercialização de Grãos: Panorama do Mercado Agrícola. Instituto de Economia Agrícola. Informações Econômicas 37: 27-32.

Nogueira Junior, S.; Tsunechiro, A. 2005. Produção Agrícola e Infra-estrutura de Armazenagem no Brasil. Informações Econômicas 35: 7-18.

Nogueira Junior, S.; Veiga Filho, A.A.; Tsunechiro, A.; Donzelli, P.L.; Alfonsi, R.R. 1989. Produção de Grãos e Armazenagem a Granel no Estado de São Paulo. Agricultura em São Paulo 36: 1-16.

Perobelli, F.S.; Vale, V.A.; Belgo, T.M.; Lanziotti, F. 2016. Avaliação Espacial das Fontes de Crescimento de um Conjunto de Commodities Agrícolas Brasileiras Exportáveis entre 2003 2013. Revista de Economia e Agronegócio 14: 1-40.

Secretaria de Estado de Agricultura e Pecuária [SEAGRO]. 2016. Agricultura. Disponível em: <http://seagro.to. gov.br/agronegocios/agricultura/>. Acesso em: 10 set. 2016.

Silva, J.S.; Campos, M.G.; Silveira, S.F. 2008. Armazenagem e comercialização de grãos no Brasil. p. 1-19. In: Silva, J.S. Secagem e Armazenagem de Produtos Agrícolas. 2ed. Aprenda Fácil. Viçosa, Minas Gerais, MG, Brasil.

Tavares, C.E.C. 2017. Estimativa do Escoamento das Exportações do Complexo Soja e Milho pelos Portos Nacionais: safra 2016/2017. Compêndio de Estudos CONAB 6: $1-23$. 